females. Only few data are available specifically focused on differences in drug use according to gender.

Objectives: To evaluate gender differences in treatment approaches in RA patients treated with bDMARDs (biological DMARDs)

Methods: We included RA patients aged $\geq 18$ years, with disease duration $\geq 1$ years, with a stable bDMARD treatment $(\geq 12$ months) in a monocentric cohort in the North-East of Italy. Social, demographic, and clinical features in addition to treatments were considered. To assess variables independently associated with gender, all variables achieving a $\mathrm{p}<0.20$ in univariate analysis were included in a multivariate regression model.

Results: Among 721 RA patients, 514 patients were eligible for the analysis and 407 were females. Compared with males, females had a lower BMI, a higher DAS28, a higher number of conventional synthetic DMARDs (csDMARDs) used before the start of bDMARDs, a higher number of bDMARDs with different mechanism of action (MoA), a larger use of prednisone and a lower rate of combination with MTX (Table 1). After adjustment for confounding factors, females had an increased probability of taking $\geq 2$ DMARDs before bDMARDs (OR 2.21, 95\% Cl 1.25-3.93, $\mathrm{p}=0.007$ ) and a lower $\mathrm{BMI}$ (per 5-unit increase, OR $0.70,95 \% \mathrm{Cl} 0.56$ $0.87, p=0.001$ ) compared to males (Figure 1).

Conclusion: In a cohort of Italian RA patients, females were treated with a higher number of csDMARDs before starting a bDMARD compared to males and a trend toward the use of more bDMARDs with different MoA. Further insight is needed regarding possible differences in the accessibility to bDMARD treatment and reasons for unsatisfactory treatment control in females.

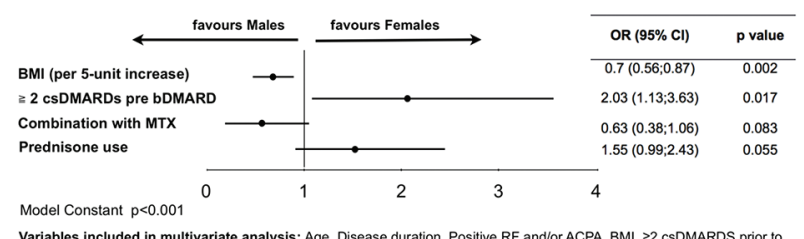
Variables included in multivariate analysis: Age, Disease duration, Positive RF and/or ACPA, BMI, 22 cSDMARDS prior to
bDMARDS, Disease activity (DAS28), Combination with MTX, PDN use, Time on DDMARDS, TNF ihnibitors use, 22 Mechanism
of action of biological drugs

Abstract THU0123 - Figure 1

Abstract THU0123 -Table 1.

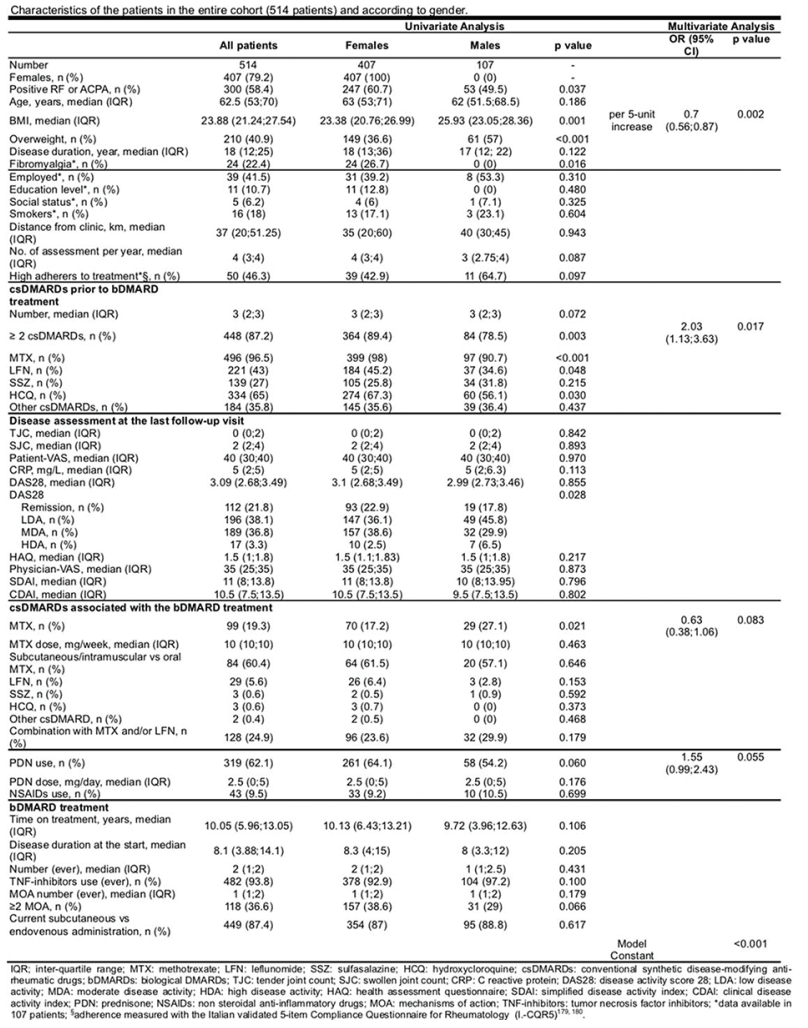

Disclosure of Interests: None declared

DOI: 10.1136/annrheumdis-2019-eular.3784

\section{THU0124 INFLUENCE OF AUTOIMMUNE VASCULITIS ON LUNG DISEASES IN RHEUMATOID ARTHRITIS - A POSTMORTEM CLINICOPATHOLOGIC STUDY OF 161 PATIENTS}

Miklós Bély ${ }^{1,1}$, Ágnes Apáthy ${ }^{2} .{ }^{1}$ Hospital of the Order of the Brothers Saint John of God in Budapest, Department of Pathology, Budapest, Hungary; ${ }^{2}$ St. Margaret Clinic, Budapest, Department of Rheumatology, Budapest, Hungary

Background: Complications of rheumatoid arthritis (RA) may modify the clinical course and symptoms of allied disorders leading to missed diagnosis or late recognition of associated diseases.

Objectives: The aim of this study was to determine the possible role of classic complications of RA: systemic autoimmune vasculitis (AV), AA amyloidosis (AAa), lethal cardiac insufficiency (Cl) caused by endo-, myoor pancarditis, with or without interstitial pneumonitis, furthermore lethal septic infection (SI) on prevalence and mortality of coexistent associated diseases: atherosclerosis (Ath), hypertension (HT), type 2 diabetes mellitus (DM), and tuberculosis (Tb) with miliary dissemination ( $\mathbf{m T b}$ ).

Methods: 234 non- selected autopsy patients with RA were studied. RA was confirmed clinically according to the criteria of the ARA.

The presence of $\mathbf{A V}, \mathbf{A A a}, \mathbf{C l}$ and $\mathbf{S I}$ was determined at autopsy and confirmed by a detailed review of extensive histological material. The prevalence and mortality of associated diseases Ath, HT, DM, Tb or mTb were determined and analyzed retrospectively, reviewing the clinical and pathological reports.

The link between $\mathbf{A V}, \mathbf{A A a}, \mathbf{C l}$ or SI and $\mathbf{A t h}, \mathbf{H T}, \mathbf{D M}, \mathbf{T b}$ or $\mathbf{m T b}$ was analyzed by $\left(\chi^{2}\right)$ test.

Results: RA was complicated by $\mathbf{A V}$ in $\mathbf{4 3}(18.4 \%)$, by $\mathbf{A A a}$ in 48 $(20.5 \%)$, by $\mathrm{Cl}$ in $15(6.4 \%)$, and by lethal $\mathrm{SI}$ in $33(14.1 \%)$ of 234 patients.

RA associated with severe Ath in 106 (45.3\%), with HT in 41 (17.5\%), with DM in $41(17.5 \%)$, with Tb in $28(11.9 \%)$ and with $\mathrm{mTb}$ in 9 (3.8\%) of 234 patients.

As a basic disease Ath led to death in $61(26.1 \%$ of 106$)$, HT in 2 $(0.9 \%$ of 41$)$, DM in none $(0 \%$ of 41$)$ and Tb with $\mathrm{mTb}$ in $3(1.3 \%$ of 28) of $\mathbf{2 3 4}$ patients. Tb without miliary dissemination was not lethal in our patient population.

The statistical links ("p" values of significance) between complications of RA and prevalence or mortality of allied disorders are summarized in Table. (*asterisk indicates a negative value of associations' coefficient with inverse relationship).

\begin{tabular}{|c|c|c|c|c|}
\hline $\begin{array}{l}\text { Complications of } \\
\text { RA }\end{array}$ & $\begin{array}{c}A V n=43 \text { of } \\
234\end{array}$ & $\begin{array}{c}\text { AAa } \mathbf{n}=\mathbf{4 8} \text { of } \\
234\end{array}$ & $\begin{array}{c}\text { CI } n=15 \text { of } \\
234\end{array}$ & SI $n=33$ of 234 \\
\hline \multicolumn{5}{|l|}{$\begin{array}{l}\text { Allied disorders in } \\
\text { RA }\end{array}$} \\
\hline Ath $n=106$ of 234 & $\begin{array}{c}\chi^{2}=6.43^{\star} \\
p<0.01\end{array}$ & $\begin{array}{c}\chi^{2}=10.04^{\star} \\
p<0.001\end{array}$ & $\begin{array}{c}\chi^{2}=0.92^{*} \\
p<0.33\end{array}$ & $\begin{array}{c}\chi^{2}=5.03^{\star} \\
p<0.02\end{array}$ \\
\hline $\begin{array}{l}\text { Ath lethal } \mathbf{n}=\mathbf{6 1} \text { of } \\
106\end{array}$ & $\begin{array}{c}\chi^{2}=15.92^{*}, \\
p<0.00\end{array}$ & $\begin{array}{c}\chi^{2}=11.04^{\star} \\
p<0.00\end{array}$ & $\begin{array}{c}\chi^{2}=4.29^{*} \\
p<0.03\end{array}$ & $\begin{array}{c}\chi^{2}=12.01^{*}, \\
p<0.00\end{array}$ \\
\hline HT 41 of 234 & $\begin{array}{c}\chi^{2}=3.20^{*} \\
p<0.07\end{array}$ & $\chi^{2}=0.03^{\star}, p<0.86$ & $\begin{array}{c}\chi^{2}=0.00^{*} \\
p<0.92\end{array}$ & $\begin{array}{c}\chi^{2}=1.27^{*} \\
p<0.25\end{array}$ \\
\hline HT lethal $n=2$ of 41 & $\begin{array}{c}\chi^{2}=0.05^{\star} \\
p<0.80\end{array}$ & $\chi^{2}=0.02, p<0.87$ & $\begin{array}{c}\chi^{2}=1.16^{*} \\
p<0.28\end{array}$ & $\begin{array}{c}\chi^{2}=0.19^{*} \\
p<0.65\end{array}$ \\
\hline DM 41 of 234 & $\begin{array}{c}\chi^{2}=0.05^{\star} \\
p<0.81\end{array}$ & $\chi^{2}=1.05^{\star}, p<0.30$ & $\begin{array}{c}\chi^{2}=0.92 \\
p<0.33\end{array}$ & $\begin{array}{c}\chi^{2}=0.01 \\
p<0.91\end{array}$ \\
\hline Tb 28 of 234 & $\begin{array}{l}\chi^{2}=4.02 \\
p<0.04\end{array}$ & $\chi^{2}=2.61^{\star}, p<0.10$ & $\begin{array}{l}\chi^{2}=0.33 \\
p<0.56\end{array}$ & $\begin{array}{l}\chi^{2}=0.37 \\
p<0.54\end{array}$ \\
\hline Tb lethal $n=3$ of 28 & $\begin{array}{c}\chi^{2}=0.00^{\star}, \\
p<0.93\end{array}$ & $\chi^{2}=0.02^{*}, p<0.86$ & $\begin{array}{c}\chi^{2}=0.53^{*}, \\
p<0.46\end{array}$ & $\begin{array}{c}\chi^{2}=0.01^{*} \\
p<0.89\end{array}$ \\
\hline $\mathrm{mTb} 9$ of 28 & $\begin{array}{l}\chi^{2}=4.24 \\
p<0.03\end{array}$ & $\chi^{2}=0.08, p<0.77$ & $\begin{array}{l}\chi^{2}=0.01 \\
p<0.91\end{array}$ & $\begin{array}{c}\chi^{2}=0.05 \\
p<0.82\end{array}$ \\
\hline $\mathrm{mTb}$ lethal $n=3$ of 9 & $\begin{array}{c}\chi^{2}=0.00^{\star} \\
p<0.93\end{array}$ & $\chi^{2}=0.02^{*}, p<0.86$ & $\begin{array}{c}\chi^{2}=0.53^{*} \\
p<0.46\end{array}$ & $\begin{array}{c}\chi^{2}=0.01^{*} \\
p<0.89\end{array}$ \\
\hline
\end{tabular}

Conclusion: The inverse correlations between $\mathbf{A V}, \mathbf{A A a}, \mathbf{C l}, \mathbf{S I}$ and $\mathbf{A t h}$ HT, DM, Tb or $\mathbf{m T b}$ indicate that the prevalence and mortality of allied disorders were not influenced basically by the complications of RA.

The consequently inverse and (in most cases) significant correlations between prevalence of $\mathbf{A V}, \mathbf{A A a}, \mathbf{C l}, \mathbf{S I}$ and the prevalence and mortality of Ath show that these are independent entities in RA. The AV, AAa, $\mathbf{C l}$ and $\mathrm{SI}$ are the most important complications of RA, and are characterize severe forms of disease, mostly involving younger patients, with an earlier onset (without pronounced atherosclerosis); while Ath is basically an age dependent phenomenon, characteristically present in RA patients with advanced age. RA patients with Ath may represent a special group of RA, characterized by lower incidence of $\mathbf{A V}, \mathbf{A A a}, \mathbf{C l}$ or $\mathbf{S I}$, and a better prognosis.

Disclosure of Interests: None declared

DOI: 10.1136/annrheumdis-2019-eular.604 